\title{
ACONTECIMENTO DISCURSIVO E MEMÓRIA DE IMAGENS NA REPRODUÇÃO DE SENTIDOS “CONTROLADOS” PELA MÍDIA
}

\author{
João Marcos Mateus Kogawa* \\ Denise Gabriel Witzel \\ Universidade Estadual do Centro-Oeste \\ Guarapuava, Paraná, Brasil
}

\begin{abstract}
Resumo: Este trabalho inscreve-se no campo da Análise do Discurso para, a partir dai, dialogar com os atuais trabalhos de Courtine, no intuito de pensar o funcionamento discursivo do imagético. Mobilizamos o conceito de intericonicidade proposto por Courtine (2011) e Chéroux (2009) para analisarmos algumas relações possiveis entre um enunciado que circulou no Facebook em 11 de setembro de 2012 e os efeitos de sentido construidos pela mídia sobre o 11 de setembro de 2001. Com efeito, o enunciado que circulou no Facebook caracteriza-se pela materialização contrastiva do 11 de setembro de 2001 e um outro: o 11 de setembro de 1973. Este último retrata o momento do golpe de Estado no Chile, financiado pelos EUA, que depôs o então presidente Salvador Allende.
\end{abstract}

Palavras-chave: Discurso. Enunciado. Intericonicidade.

\section{INTRODUÇÃO}

O acontecimento discursivo, quando observado arqueologicamente, sob a ótica de Michel Foucault, implica ruptura e/ou regularidade histórica. Para descrevê-lo, é necessário considerar, de um lado, as condições de

\footnotetext{
* Professor do Departamento de Letras. Doutor em Linguística e Língua Portuguesa pela UNESP - Araraquara (SP). Email: jmkogawa@gmail.com

** Professora do Departamento de Letras e do Programa de Mestrado em Letras. Doutora em Linguística e Língua Portuguesa pela UNESP - Araraquara (SP). Email: denisewitzel@uol.com.br
} 
existência que determinam a materialidade própria de um enunciado; de outro, sua singularidade única e aguda, interrogando como ele, o enunciado, pôde se formar historicamente e em quais realidades econômicas, sociais, culturais, políticas etc. - se articula. Assim, partindo do princípio de que o aparecimento e a formação de discursos colocam em questão o acontecimento, sua historicidade e os sentidos daí decorrentes, propomo-nos, neste trabalho, discutir o estatuto do acontecimento discursivo no campo da memória, mais precisamente, no campo da memória discursiva de imagens.

Elegemos, para esse fim, um enunciado-acontecimento com significativo valor rememorativo, na medida em que se faz/fez espetáculo na mídia e foi/é acolhido "por espectadores que não participam, mas que olham, que assistem e que, para o bem ou para o mal, se deixam arrastar por ele"1 (FOUCAULT, 1994, p. 1503, tradução nossa). Trata-se do 11 de setembro atrelado à espessura histórica de três acontecimentos: (i) $11 \mathrm{de}$ setembro de 1973 - referente ao Golpe de Estado ocorrido no Chile, culminando com a queda do regime democrático e de seu presidente Salvador Allende; (ii) 11 de setembro de 2001 - referente aos atentados terroristas contra os Estados Unidos; (iii) 11 de setembro de 2012 - referente ao texto/imagem que circulou no Facebook.

É possível pensar na atualidade, na repetibilidade e na especificidade daquele enunciado-acontecimento, questionando os mecanismos discursivos que embasam a produção de sentidos nos três momentos destacados. Nessa direção, daremos relevo à regularidade enunciativa no interior de um espaço de coexistência no qual as relações interdiscursivas e as interdependências dos sentidos asseguram a emergência do enunciado, este que efetivamente foi formulado, é único como acontecimento, mas aberto à repetição, transformação ou à reativação. Isso significa abordá-lo em sua irrupção e (re)estabelecer outros ligados "não apenas a situações que o provocam, e a consequências por ele ocasionadas, mas, ao mesmo tempo, e segundo uma modalidade inteiramente diferente, a enunciados que o precedem e o seguem" (FOUCAULT, 2007, p. 32).

\footnotetext{
${ }^{1}$ [...] spectateurs qui n'y participent pas, mais qui la regardent, qui y assistent et qui, au mieux ou au pis, se laissent entraîner par elle (FOUCAULT, 1994, p. 1503).
} 
Se o enunciado-acontecimento, além de estar ligado à escrita e à oralidade, abre "para si mesmo uma existência remanescente no campo de uma memória, ou na materialidade dos manuscritos, dos livros e de qualquer forma de registro" (FOUCAULT, 2007, p. 31-32), nosso percurso de análise será guiado pela existência remanescente de enunciados ligados à escrita e à fotografia. Isso impõe examinar os efeitos de sentido provocados por materialidades que sincretizam as linguagens verbal e não verbal; impõe, consequentemente, considerar o estatuto semiológico dos enunciados na análise do imagético, o que nos leva ao conceito de intericonicidade, associado ao conceito de interdiscursividade.

\section{REFERENCIAL TEÓRICO}

Em 1967, Foucault faz breves considerações a respeito do trabalho do alemão Erwin Panofsky, historiador de arte do século XX, que propunha novas formas de abordagem para a análise de obras de arte. Dois textos não referenciados com precisão - são evidenciados pelo filósofo francês para discutir a irredutibilidade da imagem ao texto: um sobre a Renascença, em que discute a metodologia iconográfica; outro sobre a Idade Média gótica. A novidade metodológica panofskyana consiste em repensar as relações entre o dizível e o visível, a partir de um ponto de vista que desloca a supremacia do texto sobre os elementos plásticos.

Evidentemente, isso não significa negar a importância do texto, mas instaura um equilíbrio na balança de forma que a materialidade verbal seja compreendida em relação de igualdade com a imagem. Não se trata, portanto, daquilo que determinaria de antemão o que se pode apreender diante da manifestação imagética: “[...] entrecruzamento, isomorfismo, transformação, tradução, em suma, toda essa franja do visível e do dizível que caracteriza uma cultura em um momento de sua história" (FOUCAULT, 2008, p. 79).

Foucault fala, então, ancorado nos procedimentos adotados por Panofsky, de uma sintomatologia cultural, ou seja, um procedimento de reconhecimento de formas rituais muitas vezes minimamente representadas nas imagens e nos textos que permitem diagnosticar as sensibilidades e o sistema de valores de uma determinada época. 
Essa proposta pode ser compreendida como um primeiro espaço de reflexão a partir do qual Courtine (2011) construirá o conceito de intericonicidade. Trata-se, portanto, de uma renovação na ordem do olhar do paradigma artístico-pictural. Essa renovação se deve à inserção do olhar médico - notadamente, se atentarmos para o termo sintomatologia - na observação das obras de arte que levará, posteriormente, à elaboração de noções expandidas para possibilidades de análise das formas de dominação políticas. O que Foucault (2008) esboça - sem formalização conceitual precisa - como uma sintomatologia cultural, apresenta-se, atualmente, como espaço de debates que vai além do campo da arte, englobando outras preocupações.

O termo 'sintomatologia' remete ao campo do diagnóstico e é tomado no debate sempre reiterado por Courtine (2011), a propósito da problemática que se apresenta entre semiologia linguística e semiologia médica. Para o autor, é surpreendente que nos anos 1960, ao tempo em que ocorre uma "virada linguística", a partir das reflexões sobre o signo linguístico, expandidas para vários campos das ciências humanas pelo viés semiológico saussuriano - algumas linhas do Curso de linguística geral, para sermos mais precisos - não se evidenciam os avanços da realidade panóptica do paradigma médico - e sua consequente semiologia - em prática já no final de século XIX.

O modelo arquitetônico elaborado por Bentham, retomado por Foucault em Vigiar e punir, para refletir sobre uma vigilância fundamentada na ininterruptibilidade e na invisibilidade, serve bem para exemplificar o que apontamos aqui como predominância da medicina no campo dos saberes. No modelo arquitetônico de Bentham, os prisioneiros internalizam a vigilância devido à incerteza sobre a presença do vigilante; as novas formas de dominação, por sua vez, materializam-se, ao mesmo tempo, global e individualmente. Um dos pontos de controle que rege a sociedade contemporânea é a medicina. Isso significa que o paradigma médico regula o tempo e o espaço, bem como as práticas do sujeito da atualidade. A partir daí, pensamos em uma expansão desse paradigma também no campo das ciências humanas, notadamente, no que concerne aos trabalhos atuais de Courtine. O paradigma indiciário, que se origina no 
final do século XIX, é retomado pelo autor mediante, não apenas a problematização do paradigma linguístico - crítica à semiologia barthesiana - mas também a incorporação do modelo médico ao aceitar o desafio de desenvolver o que Foucault denomina uma sintomatologia cultural e retomar o Barthes de A câmara clara.

Courtine (2011) propõe, então, uma crítica a esse domínio da visada linguística que se insere na análise das imagens, focalizando, especialmente, os primeiros trabalhos de Barthes. Se as análises de Foucault vão privilegiar, de algum modo, o paradigma médico, as de Barthes, em um primeiro momento, vão privilegiar uma forma de semiologia pautada nos moldes dos conceitos saussurianos. O ponto crítico dos trabalhos barthesianos é justamente a redução do visual ao verbal:

Um primeiro ponto: com efeito, eu parti de uma crítica da semiologia da imagem, tal como encontramos em Roland Barthes e em suas inumeráveis réplicas, porque ela assimilava a imagem ao signo linguístico, no sentido saussuriano do termo. Essa semiologia, que teve sem dúvida alguma o mérito de promover a questão da imagem e de sua análise, é a meu ver um impasse: a imagem não obedece em nada um modelo da língua ${ }^{2}$. (COURTINE, 2011, p. 38, tradução nossa).

No entanto, a obra de Barthes não é homogênea e o próprio Courtine mostra que alguns aspectos da démarche barthesiana guardam grande interesse. Sem querer afirmar que os trabalhos de Courtine são uma extensão tal qual das proposições barthesianas, existe uma tomada de posição pela negativa de trabalhos como $A$ retórica da imagem e a mobilização de conceitos formulados em $A$ câmara clara e em $O$ terceiro sentido:

${ }^{2}$ Un premier point: je suis en effet parti d'une critique de la sémiologie de l'image, telle qu'on la trouve chez Roland Barthes et dans ses innombrables répliques, parce qu'elle assimilait l'image au signe linguistique, au sens quasi-saussurien du terme. Cette sémiologielà, qui a eu sans aucun doute le mérite de promouvoir la question de l'image et de son analyse, est à mon sens une impasse: l'image n'obéit en rien à un modèle de la langue (COURTINE, 2011, p. 38) 
[...] é preciso considerar, no entanto, a pertinência das intuições ulteriores de Barthes a respeito da imagem, tais como os desenvolvimentos sobre "o obtuso" em "O terceiro sentido", ou ainda sobre o punctum em A câmara clara. Mas, não é da linguística saussuriana que essas ideias provêm, mas da psicanálise: o obtuso, ou o punctum, não são da ordem do signo, mas daquilo que falha nos signos, como o lapso quebrando as evidências da cadeia significante. Não os signos, mas os índices, os traços do surgimento de um sentido imprevisto ${ }^{3}$. (COURTINE, 2011, p. 38-39, tradução nossa).

Inserção da visada sintomatológica médica no campo de investigação do discurso. Figura uma ideia advinda de Ginzburg (2003) segundo a qual há, na virada do século XIX para o XX, a inserção dos postulados médicos no campo das humanidades. O trabalho de Ginzburg consiste em mostrar que, em um mesmo momento, três médicos - Conan Doyle, Freud e Giovanni Morelli - aplicam métodos oriundos da medicina para construir suas obras: (i) na literatura, Conan Doyle cria, baseado em um professor de medicina, o personagem Sherlock Holmes; (ii) na psicanálise, Freud descobre o inconsciente espelhando-se nos procedimentos de Morelli; (iii) este último aplica, no campo das artes, um novo método para identificação da originalidade dos quadros pautado na sintomatologia médica. É desse paradigma que compartilha o Barthes de $A$ câmara clara e de $O$ terceiro sentido.

Sob essa perspectiva, ao olhar para as imagens, Courtine (2011) mostra que é fundamental identificar os índices que remetem a outras imagens. Trata-se de lançar um olhar de investigador - e a presença da figura de Sherlock Holmes é sintomática a esse respeito (COURTINE, 2011) - que segue os traços deixados pela/na materialidade do discurso, remontando a uma memória sócio-histórica recuperável e passível de uma disposição em série.

\footnotetext{
${ }^{3}$ [...] il faut cependant reconnaitre l'intérêt chez Barthes d'intuitions ultérieures à propos de l'image, telles que les développements sur "l'obtus" dans "Le troisième sens", ou bien sur le punctum dans La chambre claire. Mais ce n'est pas de la linguistique saussurienne que ces idées proviennent, bien plus de la psychanalyse: l'obtus, ou le punctum, ne sont pas de l'ordre du signe, mais de ce qui cloche dans les signes, à la manière du lapsus venant trouer les évidences de la chaine signifiante. Pas des signes, mais des indices, des traces du surgissement d'un sens imprévu. (COURTINE, 2011, p. 38-39).
} 


\section{METODOLOGIA}

Com o intuito de construir, descrever e interpretar, pelo viés discursivo, uma série de enunciados que remetem a três períodos históricos distintos, 11 de setembro de 2012, 11 de setembro de 2001 e 11 de setembro de 1973, faremos trabalhar, doravante, o conceito de intericonicidade formulado por Chéroux (2009) e Courtine (2011). O trabalho desses autores tem, dentre outras facetas, um aspecto teórico fundamental para a compreensão do funcionamento discursivo de enunciados que ganham visibilidade e dizibilidade na mídia contemporânea. Ambos se valem desse conceito para pensar o espaço midiático operando em redes de memória que produzem, textual e imageticamente, reatualizações e ressignificações.

Nosso percurso analítico divide-se em dois momentos. Primeiramente, consideraremos a análise empreendida por Chéroux (2009) - e retomada por Courtine (2011) - que estabelece a pertinência de se pensar a divulgação midiática do 11 de setembro de 2001. Fundamentalmente, essa análise será o ponto de apoio para darmos visibilidade aos efeitos de sentido que derivam do enunciado postado no Facebook em 11 de setembro de 2012. Voltar-nos para as Torres Gêmeas significa operar com uma modalidade enunciativa de referência, a partir da qual os sentidos presentes na postagem do Facebook ganham formas e efeitos.

Destacaremos uma série cujos sentidos se pretendem estáveis para, então, analisarmos os deslizamentos e suas desestabilizações. São imagens que produzem efeitos de sentido de vitimização da posição sujeito ocupada pelos norte-americanos em 11 de setembro de 2001.

O controle de tais efeitos, inerentes ao 11 de setembro de 2001, dá-se pela depuração e divulgação de algumas imagens que remetem a outras referentes ao ataque a Pearl Harbor e à tomada de Iwo Jima pelos fuzileiros navais na guerra contra o Japão. Assim, evidenciaremos isso recuperando imagens das Torres Gêmeas envoltas por fumaça e fogo, imagem dos soldados de Iwo Jima erguendo a bandeira dos EUA, imagem dos bombeiros içando a bandeira dos EUA sobre os escombros do World Trade Center e uma cena de explosão de Pearl Harbor. 
O segundo momento consiste em considerar os deslocamentos para pensarmos o enunciado que circulou algum tempo depois do ocorrido nas Torres Gêmeas. Nesse sentido, será dado relevo ao fato de que a modalidade enunciativa que constitui o discurso de vitimização "a favor dos norte-americanos" desloca-se no enunciado de 11 de setembro de 2012 , passando a discursivizar um lugar em que os mesmos norte-americanos emergem como "vilões da história". Essa transformação na modalidade enunciativa se faz, ao mesmo tempo, pela retomada da memória das Torres Gêmeas e de algo menos recente e mais silencioso midiaticamente: o golpe que destituiu o presidente chileno Salvador Allende do poder em 11 de setembro de 1973. O enunciado que circulou no Facebook em 11 de setembro de 2012 configura-se, portanto, como um espaço de desestabilização do que foi regulado em 11 de setembro de 2001. Ao (re)atualizar a figura de Salvador Allende pela imagetização de dois "ll", substituídos pelas imagens das duas torres em processo de destruição, esse enunciado desloca os efeitos produzidos em 2001, para reposicionar o lugar atribuído anteriormente aos norte-americanos.

\section{ANÁLISE}

O enunciado 11 de setembro não é mais visto da mesma maneira se considerado antes ou depois de 2001. A data é representativa do acontecimento histórico que foi objeto, não apenas de uma ampla divulgação midiática, mas também de importantes trabalhos acadêmicos dos quais se destacam os livros Déchiffrer le corps (COURTINE, 2011) e Diplopie (CHÉROUX, 2009).

Para pensar o entrecruzamento do enunciado-acontecimento com a memória de imagens na (re)produção de sentidos controlados pela mídia, em torno do 11 de setembro, traremos algumas reflexões sobre os momentos histórico-sociais que possibilitam a emergência do 11 de setembro, circunscrevendo-o, primeiro, no episódio de 2001 e, depois, no de 1973. Essas reflexões permitirão observar a historicidade dos enunciados repetidos em 2012 e inscrevê-los nas "formas do discurso relatado por meio das quais se materializam as remissões de discursos a outros discursos" (COURTINE, 2009, p. 90). Por fim, analisaremos o enunciado-acontecimento que atualiza as duas redes de memória, antes apresentadas. 


\subsection{O QUE SE PODE E SE DEVE VISUALIZAR DO 11 DE SETEMBRO?}

Considera-se o 11 de setembro de 2001 como o acontecimento histórico de maior divulgação e midiatização da história. A partir de sua veiculação massiva na mídia contemporânea e impressa, pode-se falar em imagens-mundo e em uma mundialização das imagens (CHÉROUX, 2009). Ao mesmo tempo, nota-se, no que concerne às imagens divulgadas, uma rarificação produzida pela seleção das imagens divulgadas, pois, de uma quantidade enorme de fotografias tiradas do acontecimento, apenas algumas são veiculadas pela mídia impressa (CHÉROUX, 2009; COURTINE, 2011).

Figura 1 - Imagens que circularam na mídia impressa nos dias 12 e $13 / 09 / 2001$
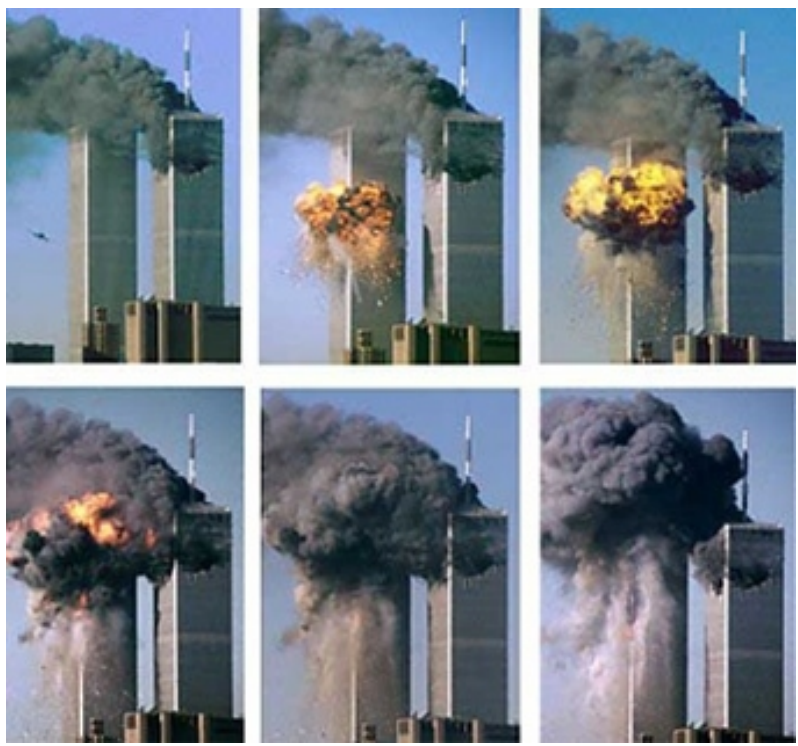

Fonte: Chéroux (2009, p. 20) 
Figura 2 - Foto de Joe Rosenthal tirada em 23/02/1945

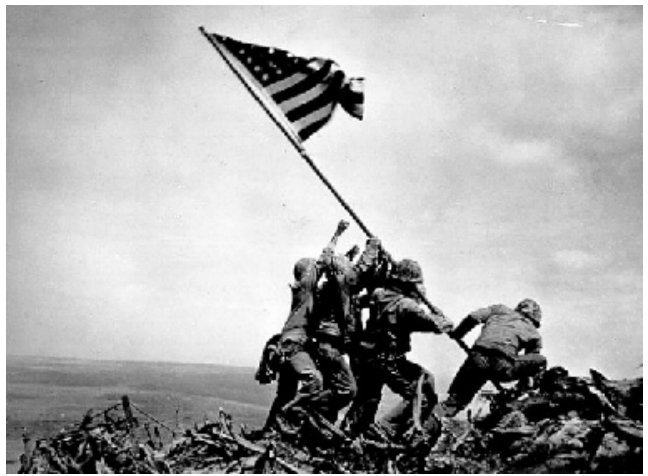

Fonte: Chéroux (2009, p. 63)

Figura 3 - Foto de Thomas Franklin tirada em 11/09/2001

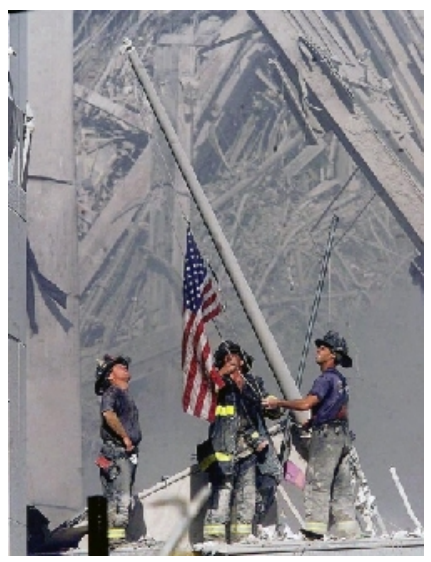

Fonte: Chéroux (2009, p. 61)

Essa visibilidade interessada, segundo os autores, produz vários efeitos de sentido, dos quais se destacam aqueles que mobilizam uma memória belicista em torno da história norte-americana. A esse respeito, a recorrência das mesmas imagens (a nuvem de fumaça, o círculo de fogo, a 
presença do avião pouco antes do choque contra as torres e os bombeiros hasteando a bandeira sobre os escombros) acionam a memória de dois outros acontecimentos, quais sejam, o ataque a Pearl Harbor (Figura 4) e a tomada de Iwo Jima (Figura 2).

\section{Figura 4 - Foto anônima tirada em 7/12/1941}

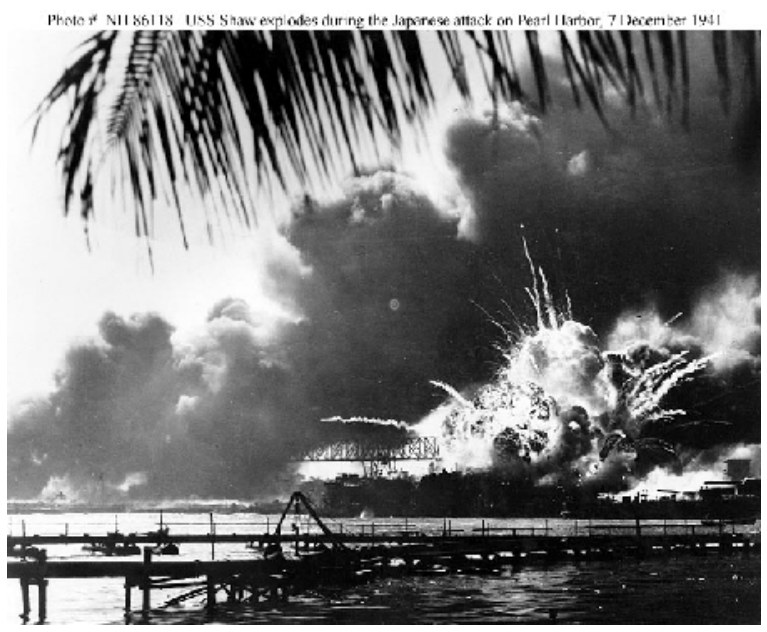

Fonte: Chéroux (2009, p. 58)

Essa produção mundial de imagens em torno do 11 de setembro, reduzidas a uma dezena, responde a um aspecto importante do funcionamento institucional de divulgação midiática. Segundo Chéroux (2009), atualmente, a produção imagética em nível mundial passa por um pequeno número de agências que detêm o poder de controlar a divulgação:

Em 1983, quando Ben H. Bagdikian escreveu The New Media Monopoly, seu livro de referência sobre essas questões de concentração, a indústria midiática era controlada por cerca de 50 empresas apenas. Dez anos depois, na ocasião da nova edição de sua obra, ele constatava que o número dessas companhias era inferior a vinte. Hoje, elas podem ser contadas nos dedos de apenas uma das mãos. AOL Time Warner, Disney, News Corporation, Viacom, 
Bertelsmann possuem, com efeito, a maior parte dos jornais, revistas, canais de televisão ou de rádio, editoras, estúdios de cinema, servidores de internet, e dividem, de fato, a quase totalidade do poder midiático ${ }^{4}$. (CHÉROUX, 2009, p. 44-45, tradução nossa).

Com base da citação acima, percebemos que as principais agências difusoras são norte-americanas e, nesse sentido, podemos pensar em uma hegemonia relativa no campo da mídia. Essa relatividade - e é importante ressaltar que o trabalho de Chéroux não se reduz a "denunciar" os espaços norte-americanos de midiatização - mostra-se em espaços outros de circulação de efeitos de sentido que problematizam a uniformização da posição-sujeito atribuída aos norte-americanos pela mídia norte-americana. Em que pese essa hegemonia, no dia 11 de setembro de 2012 circulou no Facebook uma imagem que reconvoca o acontecimento de 2001, na medida em que faz emergir, através do discurso do atentado, outro mais silencioso, que também pode ser visto sob a ótica do atentado, da invasão, do terrorismo etc.. Estamos falando sobre a retomada do 11 de setembro de 1973, no Chile, que deu lugar ao golpe de Estado, financiado pelos EUA. Como consequência, assistimos à deposição do então presidente Salvador Allende.

De acordo com Foucault (1988), não há poder que não implique resistência e, nesse aspecto, propomos uma reflexão que toma como objeto essa imagem que circulou no Facebook em 11 de setembro de 2012. Ao tomar esse objeto, acreditamos ser possível pensar, a partir do conceito de intericonicidade formulado pelos autores, no funcionamento de uma memória que, por um lado, retoma a posição hegemônica norte-americana a propósito do 11 de setembro e, por outro, reatualiza um outro

\footnotetext{
4 En 1983, lorsque Ben H. Bagdikian écrivit The New Media Monopoly, son livre de référence sur ces questions de concentration, l'industrie médiatique était alors controlé par une cinquantaine d'entreprises seulement. Dix ans plus tard, à l'occasion de la nouvelle édition de son ouvrage, il constatait que le nombre de ces sociétés était tombé au-dessus de vingt. Aujourd'hui, elles se comptent sur les doigts d'une seule main. AOL Time Warner, Disney, News Corporation, Viacom, Bertelsmann possèdent en effet la plupart des journaux, magazines, chaînes de télévision ou de radio, maisons d'édition, studios de cinéma, fournisseurs d'accès à internet, et se partagent, de fait, la quasi-totalité du pouvoir médiatique. (CHÉROUX, 2009, p. 44-45)
} 
acontecimento, qual seja, o golpe aplicado por Pinochet com apoio dos norte-americanos ao presidente Salvador Allende.

Se as imagens divulgadas após o incidente do 11 de setembro de 2001 acionam uma memória de guerra (CHÉROUX, 2009; COURTINE, 2011) em que os EUA teriam sido vítimas de atentado terrorista, a imagem que circulou no Facebook inscreve-se em outro regime de memória em que os mesmos EUA aparecem em outra posição subjetiva, justamente, naquela contrária à ocupada em 2001.

Do ponto de vista heurístico, o conceito de intericonicidade dá a ver que a materialidade discursiva visual, ao conclamar a densidade histórica, faz deslizarem os sentidos que apontam tanto para um discurso hegemônico controlador da produção imagético-midiática (só se mostra o que as grandes agências norte-americanas "autorizam"), quanto para um discurso de resistência. Assim, o Facebook será pensado, aqui, como esse lugar da resistência relativa: "[...] os circuitos da comunicação são os suportes de uma acumulação e centralização do saber; o jogo dos sinais define os pontos de apoio do poder; [...]" (FOUCAULT, 2003, p. 179).

\subsection{UM NOVO REGIME DE VISIBILIDADE: O CASO ALLENDE}

Dentre os espaços de produção/circulação discursiva, não podemos negligenciar a participação massiva que tem a rede social Facebook na sociedade atual. A heterogeneidade dos campos que aí se apresenta é enorme: publicidade, debates sobre as minorias étnicas, entretenimento. Além disso, destaca-se aquilo que nos interessa aqui, isto é, as formas de materialização dos discursos hegemônicos, mais particularmente, o norteamericano.

A esse respeito, a rede social é um importante indicador das formas de dominação presentes, hoje, em nossa sociedade. É com vistas a refletir sobre essa hegemonia norte-americana no campo da produção midiática - e também a resistência a ela - que retomamos aqui, como objeto de análise, a imagem da figura 5. Temos um enunciado que abre dois espaços de memória distintos e complementares, produzindo uma posição-sujeito paradoxal para os norte-americanos. Com efeito, eles se tornam, a um só tempo, vítimas e vilões de um atentado que, pela recorrência temporal - 
ambos os acontecimentos ocorreram no dia 11 de setembro - atualiza duas memórias sucessivas e complementares: a do 11 de setembro de 2001 mais recente, de recuperação mais fácil - e a do 11 de setembro de 1973 mais silenciosa, menos evidente e não globalizada pelas agências detentoras dos direitos de divulgação das imagens. Eis a imagem:

\section{Figura 5 - Imagem que circulou no Facebook no dia 11/09/2012}

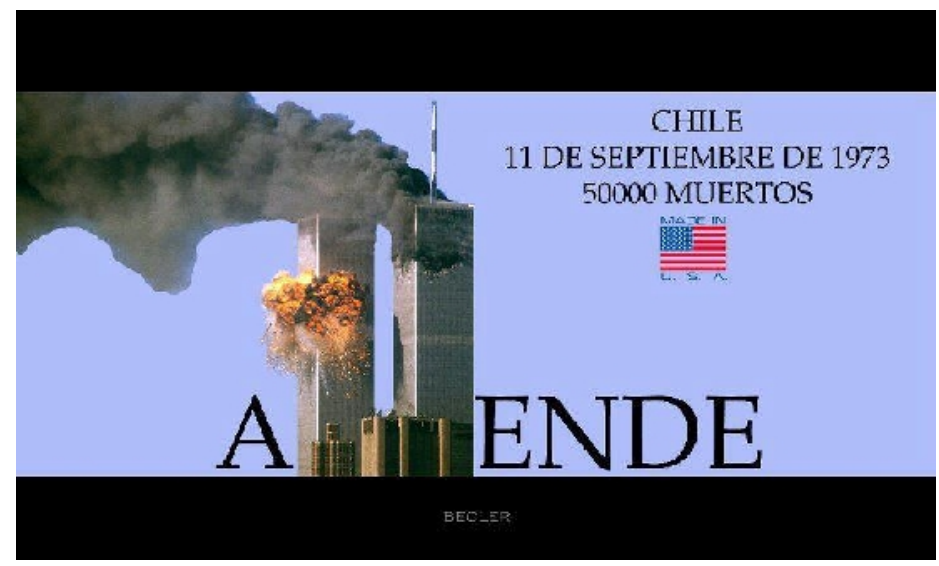

Fonte: Caros Amigos. Disponível em:

$<\mathrm{http}$ ://carosamigos.terra.com.br/index/index.php/cotidiano/2481-morte-deallende-faz-contraponto-ao-11-9-nas-redes-sociais>

A primeira observação fundamental a fazer, do ponto de vista externo à própria imagem, é que esse enunciado circulou no dia 11 de setembro de 2012, ou seja, 11 anos após o incidente de 2001. Em outros termos, a data de circulação foi justamente no dia do aniversário da queda das Torres Gêmeas. O primeiro índice a ser observado e a primeira memória a ser recuperada, quando olhamos para essa imagem, apontam para a prática da comemoração do aniversário. Prática antiga, bastante arraigada em nossa cultura, que, quase sempre, associa-se a momentos de comemoração e festejamento pela "bênção" de mais um ano de vida. 
Os gregos acreditavam que a cada ser humano se vinculava um espírito protetor ou daimôn que o assistia no seu nascimento e velava por ele durante sua vida. Esse espírito estava em relação mística com o deus cujo aniversário correspondia ao dia de nascimento do indivíduo. Os romanos também aderiram a esta ideia. [...] Essa crença seguiu seu caminho e se reencontra em noções como anjo da guarda, fada madrinha e padroeiro. [...] O costume de acender velas sobre bolos começou com os gregos. [...] Bolos de mel, redondos como a lua e iluminados por velas, eram colocados sobre os altares do templo de Artêmis. [...] A crença popular atribui às velas de aniversário o poder mágico de realizar os desejos. [...] As velas acesas e os fogos de artifício sempre tiveram uma significação mística particular desde que o home começou a erigir altares aos seus deuses. As velas são, então, uma homenagem à criança que comemora seu aniversário; elas lhes honram e lhes dão sorte. [...] Os desejos de aniversário e os votos de felicidade fazem parte da festa. [...] Essa crença tem raízes na magia. [...] Os desejos de aniversário podem fazer bem ou mal por que estamos mais próximos do mundo dos espíritos nesse momento preciso ${ }^{5}$.

Não é nosso objetivo aqui traçar a história do aniversário, mas retomar, ainda que rapidamente, a história dessa prática e mostrar que a data de circulação da imagem no Facebook (11 de setembro de 2012) não é aleatória, na medida em que é associada a essa prática antiga. A citação acima nos permite refletir, para além da ideia de uma prática marcada pelas

\footnotetext{
${ }^{5}$ Les Grecs croyaient qu'à chaque humain s'attachait un esprit protecteur ou daimôn qui assistait à sa naissance et veillait sur lui durant sa vie. Cet esprit était en relation mystique avec le dieu dont l'anniversaire correspondait au jour de naissance de l'individu. Les Romains aussi souscrivaient à cette idée. [...] Cette croyance a fait son chemin et se retrouve dans les notions d'ange gardien, de marraine fée et de saint patron. [...] La coutume consistant à allumer des bougies sur les gâteaux a commencé avec les Grecs. [...] Des gâteaux de miel, ronds comme la lune et éclairés par des cierges, étaient déposés sur les autels du temple d'Artémis. [...] La croyance populaire attribue aux bougies d'anniversaire le pouvoir magique d'exaucer les souhaits. [...] Les cierges al ]lumés et les feux sacrificiels ont toujours eu une signification mystique particulière depuis que l'homme a commencé à dresser des autels à ses dieux. Les bougies sont donc un hommage à l'enfant qui fête son anniversaire; elles lui font honneur et lui portent chance. [...] Les souhaits d'anniversaire et les vœux de bonheur font partie intégrante de la fête. [...] Cette croyance prend ses racines dans la magie. [...] Les souhaits d'anniversaire peuvent faire du bien ou du mal parce que l'on est plus proche du monde des esprits à ce moment précis. (LINTON; LINTON; 1957, p. 8, 18-20. Disponível em: <http://fr.wikipedia.org/wiki/Anniversaire>.)
} 
regras do capitalismo, sobre um espaço ritualístico ancorado em uma aura mística: fazer pedidos ao assoprar as velas, momento de "zerar a vida e começar de novo".

Momento de comemoração, de festa, de alegria, mas também de fechamento de ciclo, de etapa cumprida, de "início de uma nova vida". Todas essas memórias podem ser convocadas quando pensamos no dia de circulação do enunciado em questão. Sob essa ótica, dentre outros efeitos de sentido, instauram-se dois antagônicos que definem a raridade do enunciado: um que se vincula à discursivização de um ato comemorativo algo da ordem da positividade que considera o evento um "chega pra lá" na hegemonia norte-americana - e outro de retomada de um espaço de homenagem às vítimas do 11 de setembro de 2001. Assim, a materialidade analisada agrega, ao mesmo tempo, retomada do discurso hegemônico norte-americano e rompimento com ele. Se, por um lado, o 11 de setembro significa um momento dramático da história norte-americana, por outro, significa também o acontecimento em que os EUA figuram, não como vítimas, mas como "vilões".

Ao nos deslocarmos para o espaço interno do enunciado - uma vez que sua data de circulação implica algo que o constitui externamente - o primeiro espaço discursivo a ser retomado é o dos discursos produzidos nos dois dias que seguiram ao ataque às Torres Gêmeas. Ataque, atentado, dia de infâmia, termos que poderiam ser utilizados para resumir a forma como o acontecimento foi massivamente divulgado pela mídia. Os EUA foram agredidos, vítimas de um "ato covarde de violência" que feriu não apenas os próprios norte-americanos, mas também outros países do mundo, na medida em que o World Trade Center estava repleto de estrangeiros.

Retomamos o trecho de Foucault (2003) que citamos anteriormente: a tecnologia - a comunicação como ponto de centralização do saber - faz surgir os pontos de apoio do poder. Assim, pelo funcionamento desse saber que produz, edita, reformula e faz circular imagens, depreendemos os jogos de poder que regulam o que pode/deve ser mostrado ao mundo.

Não é necessário, efetivamente, um grande esforço para recuperar a memória do acontecimento das Torres Gêmeas. Se traçarmos linhas 
diretivas nessa imagem dos quatro vértices até o centro, teremos um ponto quase exatamente no centro em que a imagem das torres em chamas se apresenta. Centralização que reitera, portanto, a recuperação imediata da memória mais recente. É aquilo que nos atinge e nos faz retomar a posição vitimizada já conhecida e massivamente divulgada dos norte-americanos.

Tal centralização é fundamental porque esse mesmo movimento faz ressaltar a memória das Torres Gêmeas. Concomitante e estrategicamente, faz ressurgir a outra memória, mais silenciosa e quase despercebida. Vemos, pois, uma centralização ancorada em algumas letras à esquerda e à direita cuja leitura horizontal dá forma ao enunciado Allende. Diante disso, é inevitável a inquietação diante da possibilidade de um desconhecimento em relação a esse dizer. Se a imagem das duas torres é tão conhecida, o que significa essa associação com os dois "ll"? O que é ou quem foi Allende?

Uma rápida pesquisa resolve a questão: trata-se de Salvador Allende, presidente do Chile, anterior a Pinochet. Ele foi vítima de um golpe de Estado em 1973. Vemos, então, delinear-se outro trajeto de leitura, associado a outra memória discursiva, aquela do golpe de 11 de setembro de 1973 e seu financiamento pelos mesmos EUA atacados em 2001. Eis o ponto nodal que singulariza o enunciado em questão: pelo jogo intericônico entre as Torres Gêmeas em chamas e os dois "ll do sobrenome do presidente chileno" - tornados imagem -, instaura-se a hegemonia e a resistência. Como afirma Foucault (1988): não há poder sem resistência.

Essa divisibilidade do enunciado é reforçada por outros elementos. Destacamos, para finalizar, a presença do selo composto pela bandeira dos EUA e pelo dizer Made in USA. Trata-se de um enunciado que circula no campo industrial para especificar o lugar de fabricação de um produto. Novo espaço dividido, pois, ao mesmo tempo, Made in USA alude ao $11 \mathrm{de}$ setembro de 2001 e ao 11 de setembro de 1973. Novo espaço paradoxal, na medida em que o "feito nos EUA" é, ao mesmo tempo, o espaço em que o acontecimento se deu, portanto, os EUA como pacientes, mas também o espaço em que o golpe de 1973 foi maquinado, planejado e financiado. Os EUA, portanto, como executores da ação. 


\section{CONSIDERAÇÕES FINAIS}

Ao traçarmos esse percurso analítico, visamos elucidar a pertinência do conceito de intericonicidade para pensarmos a mídia e as redes sociais quando essas reestabelecem discursos que nos incitam a refletir sobre alguns efeitos ditatoriais no campo do imagético.

A partir do que foi exposto, podemos compreender que a imagem que circulou no Facebook, no dia 11 de setembro de 2012, permite um olhar sobre a divisibilidade de um enunciado que se constrói a partir de dois posicionamentos distintos: um que reitera o discurso hegemônico norteamericano dado a ver /ler nos dias subsequentes ao 11 de setembro de 2001 e outro que apresenta o discurso de resistência a esse, qual seja, o do 11 de setembro de 1973.

Essa construção, que singulariza o enunciado em questão, ocorre por meio do jogo intericônico que se estabelece fundamentalmente na imagetização dos dois "ll” tornados Torres Gêmeas. Isto é, ao associar os dois "ll" às Torres, constrói-se um espaço e um tempo divididos: EUA 11/10/2001 x Chile 11/10/1973. Essa ambiguidade espaço-temporal reforça-se também pelo selo com a "marca registrada dos EUA": como sujeitos pacientes ou como agentes, os EUA são o espaço de fabricação. Como agentes, fazem do Chile - e de Allende - os pacientes. Memória ofuscada, uma vez que não divulgada pela mídia, espaço de saber que dá suporte aos jogos do poder. É importante retomar o estudo de Chéroux (2009), na medida em que ele mostra que essa regulação das imagens - e especialmente das imagens já que esse é o espaço primordial para o controle via direitos autorais - é institucionalmente determinada pelos aparelhos norte-americanos. Warner, Universal, entre outras, são os crivos que ditam o que pode e o que não pode ser mostrado em matéria de imagens. Isso ocorreu, efetivamente, na divulgação do acontecimento do 11 de setembro de 2001.

Chéroux nos incita a refletir por que, dentre inúmeras imagens feitas a respeito do acontecimento, apenas algumas foram divulgadas (as cenas do círculo de fogo provocado pela explosão dos tanques dos aviões, a nuvem de fumaça e a cena dos aviões momentos antes de se chocarem contra as 
Torres). Com efeito, não foram apenas essas que foram feitas no dia do acontecimento. Várias câmeras apreenderam aquele momento e inúmeras fotos foram enviadas às agências, no entanto, apenas umas poucas circularam.

Sob essa ótica, se por um lado, o 11 de setembro de 2001 foi constantemente retomado e divulgado - oferecendo ao mundo "a versão norte-americana" da história - pelos jornais, revistas e pela televisão, em 11 de setembro de 2012, temos a retomada desse discurso no espaço do Facebook de maneira ressignificada. A esse respeito, a rede social apresenta-se como espaço de resistência.

No âmbito de nossa proposta de análise, acreditamos ter sido pertinente, portanto, retomar o conceito de intericonicidade (COURTINE, 2011; CHÉROUX, 2009), a partir do qual a visada da semiologia médica assentada na busca pelos índices se apresenta como fundamental. No entanto, embora haja essa marca da inserção da medicina no campo de estudos do discurso, não se trata de apagar ou minimizar a importância da Linguística ou do linguístico enquanto espaço de reflexão em torno do discursivo. Trata-se, efetivamente, de agregar ao tronco conceitual de uma reflexão discursiva um elemento conceitual que permite explicitar a pertinência e o lugar do visual.

\section{REFERÊNCIAS}

CHÉROUX, C. Diplopie: l'image photographique à l'ère des médias globalisés: essai sur le 11 de septembre 2001. Paris: LePointduJour, 2009.

COURTINE, J.-J. Déchiffrer le corps: penser avec Foucault. Grenoble: Jérôme Millon, 2011.

FOUCAULT, M. As palavras e as imagens. In: Ditos e escritos II: arqueologia das ciências e história dos sistemas de pensamento. Organização e seleção dos textos: Manoel Barros da Mota.Trad. bras. Elisa Monteiro. 2. ed. Rio de Janeiro: Forense, 2008. p. 78-81.

. A arqueologia do saber. Rio de Janeiro: Forense, 2007.

. Vigiar e punir. Rio de Janeiro: Vozes, 2003.

. Qu'est-ce que les Lumières? In: FOUCAULT, M. Dits et écrits. Paris:

Gallimard, 1994, p. 1498-1507. 
1988.

. História da Sexualidade 1: a vontade de Saber. Rio de Janeiro: Graal,

LINTON, R.; LINTON, A. The lore of birthdays. Disponível em:

$<$ http://fr.wikipedia.org/wiki/Anniversaire>. Acesso em: 8 out. 2012.

\section{BIBLIOGRAFIA CONSULTADA}

BARTHES, R. A câmara clara. Nota sobre a fotografia. Trad. Bras. Júlio Castañon Guimarães. Rio de Janeiro: Nova Fronteira, 1984.

A retórica da imagem. In: . O óbvio e o obtuso: ensaios críticos.

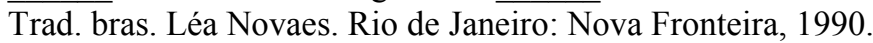

. O terceiro sentido. In: . O óbvio e o obtuso: ensaios críticos. Trad. bras. Léa Novaes. Rio de Janeiro: Nova Fronteira, 1990.

MILANEZ, N. O corpo é um arquipélago: memória, intericonicidade e identidade. In: NAVARRO, P. (Org.) Estudos do texto e do discurso: mapeando conceitos e métodos. São Carlos: Claraluz, 2006. p. 153-179.

\section{Recebido em: 16/01/13. Aprovado em: 19/08/13.}

Title: Discursive event and imagetic memory in the reproduction of meanings "controlled" by the media Authors: João Marcos Mateus Kogawa; Denise Gabriel Witzel Abstract: Based on Discourse Analysis, this paper dialogues with the current works by Courtine, with the purpose of thinking about the discourse function of the imagetic. We use the concept of intericonicity as proposed by Courtine (2011) and Cheroux (2009) to analyze some of the possible relations between the enunciation that circulated on Facebook on Sept 11, 2012 and the effects upon meaning about Sept 11, 2001 that were produced by the media. Actually, the enunciation that circulated on Facebook is characterized by the contrastive materialization of the Sept. 11, 2001, as well as by another event that occurred on Sept. 11, 1973. The latter concerns to the moment when Salvador Allende, the Chilean President at that time, was overthrown in a coup d'état that was financed by the United States.

Key words: Discourse. Enunciation. Inter-iconicity. 
Título: Suceso discursivo y memoria de imágenes en la reproducción de sentidos "controlados" por los medios Autores: João Marcos Mateus Kogawa; Denise Gabriel Witzel

Resumen: Este trabajo se inscribe en el campo del Análisis del Discurso para, a partir de ahí, dialogar con los actuales trabajos de Courtine, en la intención de pensar el funcionamiento discursivo del imagético. Movilizamos el concepto de intericonicidad propuesto por Courtine (2011) y Chéroux (2009) para que analicemos algunas relaciones posibles entre un enunciado que circuló en Facebook el 11 de septiembre de 2012 y los efectos de sentido construidos por los medios sobre el 11 de septiembre de 2001. Con efecto, el enunciado que circuló en Facebook se caracteriza por la materialización contrastante del 11 de septiembre de 2001 y otro: el 11 de septiembre de 1973. Este último retrata el momento del golpe de Estado en Chile, financiado por los E.E.U.U. que derrocó al entonces presidente Salvador Allende.

Palabras-clave: Discurso. Enunciado. Intericonicidad. 